\title{
Kaposiform lymphangiomatosis and kaposiform hemangioendothelioma: similarities and differences
}

\author{
$\mathrm{Yi} \mathrm{Ji}^{\mathrm{i}^{*+}}$ (D), Siyuan Chen ${ }^{2^{*}+}$, Suhua Peng ${ }^{1}$, Chunchao Xia ${ }^{3}$ and $\mathrm{Li} \mathrm{Li}^{4}$
}

\begin{abstract}
Background: Kaposiform lymphangiomatosis (KLA) and kaposiform hemangioendothelioma (KHE) are rare and aggressive vascular disorders. The aim of this study was to examine the clinical features and prognosis of KLA and KHE involving the thorax.

Methods: The clinical features, imaging and pathological findings, treatments and outcome were retrospectively reviewed for 6 patients with KLA and 7 patients with KHE involving the thorax.

Results: The mean ages at the time of the presentation of signs/symptoms were 26.7 months and 4.1 months for $\mathrm{KLA}$ and KHE, respectively. Respiratory symptoms, pericardial and pleural effusion, thrombocytopenia and coagulopathy were common in both KLA and KHE. Diffuse lesions involving the lung and extrathoracic sites were observed in KLA but not in KHE. Histopathologically, all lesions had spindled tumor cells, which were immunoreactive for CD31 and D2-40. In KLA, the spindle cells were distributed in sparse and poorly marginated clusters, whereas the spindle cells formed more defined and confluent vascularized nodules in KHE. Unlike the refractory behavior of KLA, the majority of patients with KHE responded to medical treatments with regression of the lesion and normalization of the hematologic parameters.

Conclusions: The presenting and histological characteristics of KLA can overlap with those of KHE. The presence of diffuse vascular lesions in the mediastinum and lung with refractory thrombocytopenia and coagulopathy should suggest the diagnosis of KLA. Given the rarity and high morbidity and mortality of these disorders, the diagnostic process and therapeutic approach should include a multidisciplinary team review and consensus.
\end{abstract}

Keywords: Kaposiform lymphangiomatosis, Kaposiform hemangioendothelioma, Thrombocytopenia, Coagulopathy, Thorax

\section{Introduction}

Kaposiform lymphangiomatosis (KLA) and kaposiform hemangioendothelioma (KHE) are rare vascular anomalies, both of which have locally aggressive characteristics. These two types of vascular anomalies can present at birth or shortly after birth and are associated with high morbidity and mortality [1-3]. KLA can be localized to

\footnotetext{
* Correspondence: jiijiyuanyuan@163.com; siy_chen@163.com

${ }^{\dagger}$ Yi Ji and Siyuan Chen contributed equally to this work.

${ }^{1}$ Division of Oncology, Department of Pediatric Surgery, West China Hospital of Sichuan University, Chengdu 610041, China

${ }^{2}$ Pediatric Intensive Care Unit, Department of Critical Care Medicine, West China Hospital of Sichuan University, \#37\# Guo-Xue-Xiang, Chengdu 610041, China

Full list of author information is available at the end of the article
}

the mediastinum and lung, or most often, can be widespread with the involvement of multiple extrathoracic organs. KHE is found in varied locations, but there is a predilection for the extremities and trunk. Clinically, KLA and KHE are often associated with life-threatening thrombocytopenia and consumptive coagulopathy. Histopathologically, KLA and KHE are characterized by spindled endothelial cells and malformed lymphatic channels $[2,4]$. The natural histories of these disorders and the appropriate treatment regimen remain controversial.

KHE involving the thorax is extremely rare, with few cases reported in the literature [5-7]. However, KHE involving the thorax can share overlapping characteristics

(C) The Author(s). 2019 Open Access This article is distributed under the terms of the Creative Commons Attribution 4.0 International License (http://creativecommons.org/licenses/by/4.0/), which permits unrestricted use, distribution, and 
in terms of clinical symptoms (e.g., respiratory distress), anatomical location, imaging findings and complications (e.g., pleural and pericardial effusions) with KLA. Given the rarity, clinical similarities and sometimes confusing histopathologic findings between KLA and KHE, these diseases can be misclassified or overlooked. Therefore, the objective of our study was to describe and analyze the characteristics of these vascular disorders. More precise recognition of the distinct features of KLA and KHE will facilitate their diagnosis and the prompt application of pharmacologic interventions.

\section{Methods}

Institutional review board approval for this retrospective study was obtained from the West China Hospital of Sichuan University. All procedures followed the research protocols approved by West China Hospital of Sichuan University and Sichuan University and were conducted according to the Declaration of Helsinki. Written informed consent was obtained from the parents of all patients.

The study included patients with KLA and patients with KHE involving the thorax. All patients were diagnosed and followed at the West China Hospital of Sichuan University over a 15 -year period between January 2003 and December 2017. The diagnoses of KLA and KHE were based on clinical presentation/features, imaging studies and/or histological data [2, 8, 9]. Based on the findings of computed tomography (CT) scans and/or magnetic resonance imaging (MRI), only KHEs with thoracic involvement were included. Part of the KHE cohort was included in our previous study [4]. Patients were excluded if they had insufficient data.

Data obtained from the medical records included demographics, clinical presentation, associated complications, laboratory results, imaging results, treatment, follow-up examinations and outcome. According to previous studies, the Kasabach-Merritt phenomenon (KMP) in KHE was defined as a platelet count less than $100 \times 10^{9} / \mathrm{L}$ with consumptive coagulopathy and hypofibrinogenemia. Severe acquired hypofibrinogenemia was defined as a fibrinogen (FIB) level less than $1.0 \mathrm{~g} / \mathrm{L}$. Severe anemia was defined as a hemoglobin concentration less than $80 \mathrm{~g} / \mathrm{L}$ [10]. Elevated D-Dimer was defined as a test result more than $500 \mu \mathrm{g} / \mathrm{L}$. Prolonged prothrombin time (PT) and active partial thromboplastin time (APTT) were defined as values above 15 and $40 \mathrm{~s}$, respectively. Associated chronic pain was defined as daily pain for at least 3 months. Response to therapy was classified as successful, stabile and worse. Based on previous studies, a successful treatment response was defined as an improvement in the patient's symptoms and/or complications, the restoration of hematologic parameters, and a reduction in the lesion volume [11].

\section{Results}

\section{Baseline characteristics}

Thirteen patients were included in the study. A summary of the patients is presented in Table 1. For additional details regarding the clinical characteristics of the patients see the Additional file 1: Table S1. Of these 13 patients, six were diagnosed with KLA. The mean age at diagnosis of KLA was 52.8 months (range 13.0 to 108.0 months). There were four males and two females. Two patients initially presented with non-productive cough and fatigue. These patients had diffuse pulmonary opacities on chest radiography and were suspected to have a pulmonary infection. Multiple courses of antibiotic therapy were administered, but their condition did not improve after treatment. Another two patients were first admitted to local hospitals for increasing signs of respiratory distress. The remaining two patients did not have respiratory signs or symptoms; one presented with

Table 1 Demographic and Clinical Characteristics of patients with KLA and KHE ${ }^{\mathrm{a}}$

\begin{tabular}{|c|c|c|}
\hline \multirow[t]{2}{*}{ Variables } & KLA & $\mathrm{KHE}$ \\
\hline & $n=6$ & $n=7$ \\
\hline \multicolumn{3}{|l|}{ Patients } \\
\hline \multicolumn{3}{|l|}{ Gender $^{\mathrm{b}}$} \\
\hline Male & $2(33.3)$ & 2 (28.6) \\
\hline Female & $4(66.7)$ & $5(71.4)$ \\
\hline \multicolumn{3}{|c|}{ Age at the time of the presentation of the signs and/or symptoms ( $m$} \\
\hline Mean (range) & $26.7(8.0-72.0)$ & $4.1(0.0-10.0)$ \\
\hline \multicolumn{3}{|l|}{ Age at diagnosis (m) } \\
\hline Mean (range) & $52.8(13.0-108.0)$ & $6.5(0.3-14.0)$ \\
\hline \multicolumn{3}{|l|}{ Vascular lesions } \\
\hline \multicolumn{3}{|l|}{ Involvement ${ }^{\mathrm{b}}$} \\
\hline Skin & $1(16.7)$ & $4(57.1)$ \\
\hline Lung & $5(83.3)$ & $0(0.0)$ \\
\hline Bones & $4(66.7)$ & $4(57.1)$ \\
\hline Peritoneal cavity & $3(6.3)$ & $0(0.0)$ \\
\hline \multicolumn{3}{|l|}{ Manifestation $^{\mathrm{b}}$} \\
\hline Focal & $0(0.0)$ & $6(85.7)$ \\
\hline Multifocal & $0(0.0)$ & $1(14.3)$ \\
\hline Diffuse & $6(100.0)$ & $0(0.0)$ \\
\hline \multicolumn{3}{|l|}{ Follow-up (y) } \\
\hline Mean (range) & $4.8(3.2-6.0)$ & $4.3(1.2-9.0)$ \\
\hline \multicolumn{3}{|l|}{ Outcome $e^{b}$} \\
\hline Improved & $1(16.7)$ & $6(85.7)$ \\
\hline Stable & $1(16.7)$ & $0(0.0)$ \\
\hline Worse & $2(33.3)$ & $0(0.0)$ \\
\hline Death & $2(33.3)$ & $1(14.3)$ \\
\hline
\end{tabular}

${ }^{a} K L A$ kaposiform lymphangiomatosis, KHE kaposiform hemangioendothelioma; ${ }^{b}$ Values are presented as the number of cases (percentage) 
abdominal distention and vomiting, and the other presented with progressive cutaneous bruising and a subcutaneous mass.

KHE was reported in 7 patients, including 5 males and 2 females. The median age at the time of the presentation of signs and/or symptoms was 4.1 months (range 0.0 to 10.0 months). The median age at diagnosis of KHE was 6.5 months (range 0.3 to 14.0 months). Four patients initially presented with cutaneous abnormalities that ranged from an erythematous papule, plaque, or nodule to an indurated firm purple mass. In these four patients, cutaneous signs proceeded tumor recognition in 2 patients. Another three patients did not have cutaneous involvement. The initial presenting features in these non-cutaneous patients included respiratory symptoms $(2 / 3)$ and increased listlessness with decreased appetite $(1 / 3)$.

\section{Hematological parameters}

Routine blood parameters and coagulation function were monitored regularly in all patients. Five patients with KLA had confirmed thrombocytopenia, with a mean lowest platelet level of $41 \times 10^{9} / \mathrm{L}$ (range 3 to $75 \times 10^{9} / \mathrm{L}$ ) during the diagnostic period; three patients had no evidence of thrombocytopenia at the initial assessment, but thrombocytopenia developed later (Table 2); two patients presented with severe thrombocytopenia at the initial assessment. All patients with KHE sustained KMP. The mean lowest platelet count was $13 \times 10^{9} / \mathrm{L}$ (range 4 to $26 \times 10^{9} / \mathrm{L}$ ).

Acquired severe hypofibrinogenemia (a FIB level less than $1.0 \mathrm{~g} / \mathrm{L}$ ) was observed in four patients with KLA and six patients with KHE. Two patients with KLA and three patients with KHE had severe anemia (hemoglobin concentration less than $80 \mathrm{~g} / \mathrm{L}$ ). All patients with $\mathrm{KHE}$ presented with increased levels of D-dimer. Increased PT and APTT were common in patients with KHE.

\section{Imaging features}

CTs and/or MRIs were available for all patients. All patients with KLA had mediastinal involvement. Five patients with KLA had diffuse lesions involving the lung. On thoracic CT scan, the typical imaging finding of KLA was infiltrative soft-tissue thickening (Fig. 1a). MRI showed extensive bilateral ground-glass opacities, thickening of the interlobular septa, and bronchovascular bundles (Fig. 1b). Moderate to severe pericardial effusions (Fig. 1b), pleural effusions (Fig. 2a) and pleural thickening (Fig. 2c) were prevalent. Multiple splenic vascular lesions were identified in two patients (Fig. 1c), including one with lesions simultaneously involving the mesentery, pancreas and liver. Bone invasion or destruction was common (4/6); vertebrae destruction (3/6) and invasion of multiple ribs $(2 / 6)$ or the pelvis $(1 / 6)$ was observed (Fig. 2b). One patient (1/6) had lesions involving the ilium, ischium and femur.

On unenhanced CT scans, the classic appearance of KHE with cutaneous involvement was that of a homogenous mass (Fig. 3). The mass exhibited isoattenuation with the adjacent muscle and extended into the subcutaneous tissues, bones, muscles and mediastinum, with ill-defined margins. On MRI, KHE lesions typically appeared as heterogeneous hyperintense masses. Mild to moderate pericardial effusion was

Table 2 Comparison of hematological parameters at the time of lowest recorded platelet count ${ }^{\mathrm{a}}$

\begin{tabular}{|c|c|c|c|c|c|c|c|}
\hline Cases & $\mathrm{PLT}\left(\times 10^{9} / \mathrm{L}\right)$ & $\mathrm{HGB}(\mathrm{g} / \mathrm{L})$ & WBC $\left(\times 10^{9} / L\right)$ & $\mathrm{FIB}(\mathrm{g} / \mathrm{L})$ & PT (sec) & APTT (sec) & D-Dimer $(\mu \mathrm{g} / \mathrm{L})$ \\
\hline \multicolumn{8}{|l|}{$K L A$} \\
\hline 1 & 30 & 77 & 11.2 & 0.49 & 10.5 & 34.3 & 674 \\
\hline 2 & 3 & 92 & 5.9 & 0.42 & 16.8 & 50.2 & 3329 \\
\hline 3 & 75 & 83 & 7.9 & 1.44 & 12.2 & 36.8 & 820 \\
\hline 4 & 41 & 58 & 9.4 & 0.61 & 12.7 & 44.5 & 5066 \\
\hline 5 & 58 & 92 & 15.8 & 0.75 & 18.6 & 64.2 & 1087 \\
\hline 6 & 215 & 119 & 18.2 & 2.78 & 12.4 & 36.8 & 20 \\
\hline \multicolumn{8}{|l|}{ KHE } \\
\hline 7 & 9 & 105 & 8.9 & $<0.10$ & 27.8 & 68.9 & 8215 \\
\hline 8 & 21 & 88 & 13.3 & 0.51 & 11.0 & 35.3 & 1996 \\
\hline 9 & 7 & 69 & 23.5 & 0.40 & 25.3 & 51.8 & 3744 \\
\hline 10 & 7 & 55 & 7.2 & 0.22 & 30.2 & 70.2 & 11,805 \\
\hline 11 & 26 & 91 & 15.6 & 1.67 & 10.7 & 47.6 & 718 \\
\hline 12 & 4 & 68 & 6.9 & 0.57 & 15.6 & 56.0 & 2354 \\
\hline 13 & 17 & 102 & 9.3 & 0.98 & 12.0 & 38.6 & 903 \\
\hline
\end{tabular}

${ }^{a} K L A$ kaposiform lymphangiomatosis, KHE kaposiform hemangioendothelioma, $P L T$ platelet, $H G B$ hemoglobin, WBC white blood cell, FIB fibrinogen, $P T$ prothrombin time, APTT active partial thromboplastin time 

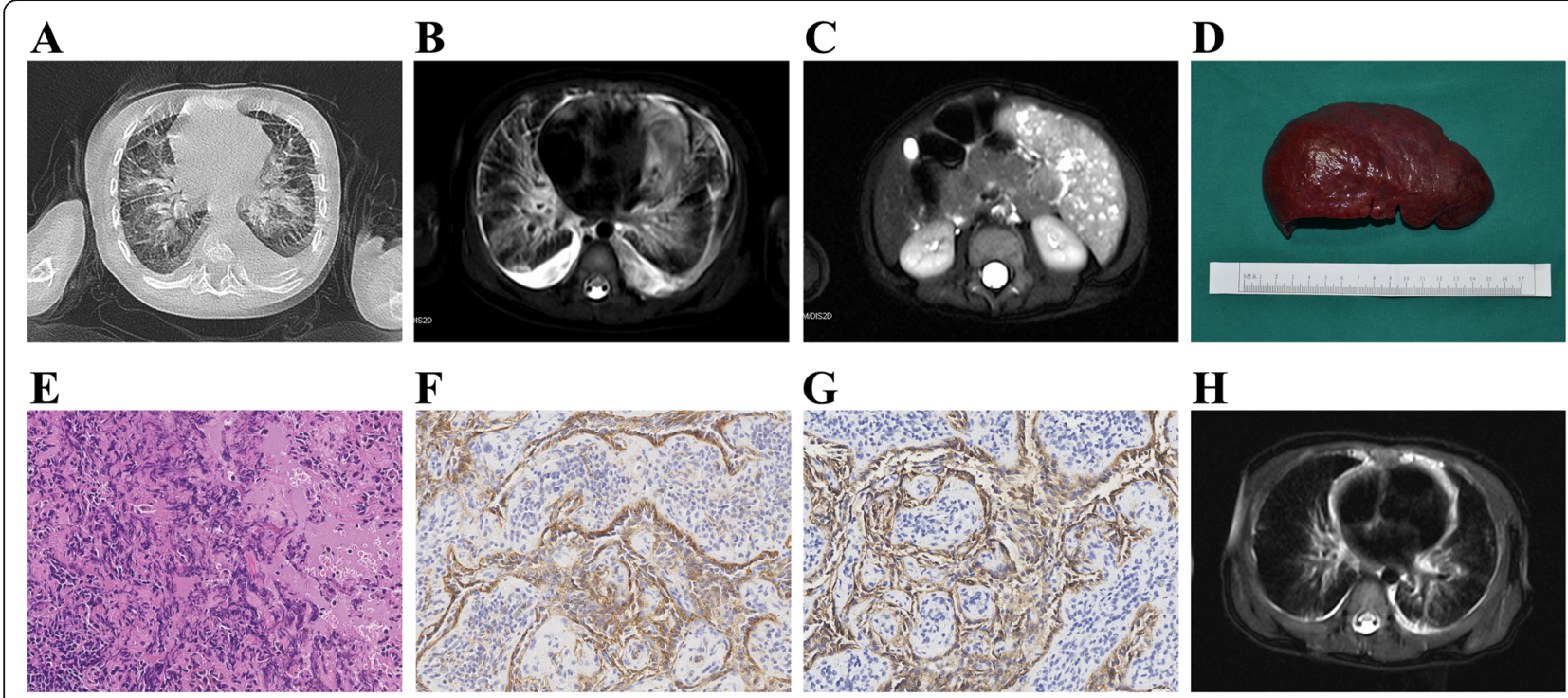

\section{$\mathbf{H}$}

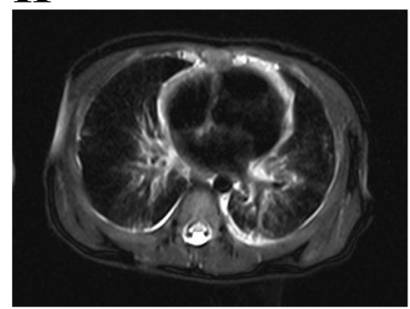

Fig. 1 Radiologic findings and pathological features in KLA (Patient \#3). a Unenhanced CT scan of the chest demonstrates thickening of the interlobular septa. Axial T2-weighted thoracic MRI shows pericardial effusion and high-signal abnormality in the mediastinum that extends along the bronchovascular bundles (b). Axial T2-weighted MRI of the abdomen shows multiple high-signal splenic lesions (c). Macroscopic view of the spleen excised from the patient (d). Multiple, small, reddish blue nodules are noted on the surface of the spleen. Hematoxylin-eosin staining shows dilated lymphatic channels and dispersed small irregular cellular clusters within the splenic parenchyma. The clusters are comprised of spindle-like cells without distinct lumens e. The spindle-like cells are immunopositive for CD31 (F) and D2-40 g. 6 months after splenectomy, MRI revealed a significant involution of the lesion $\mathbf{h}$

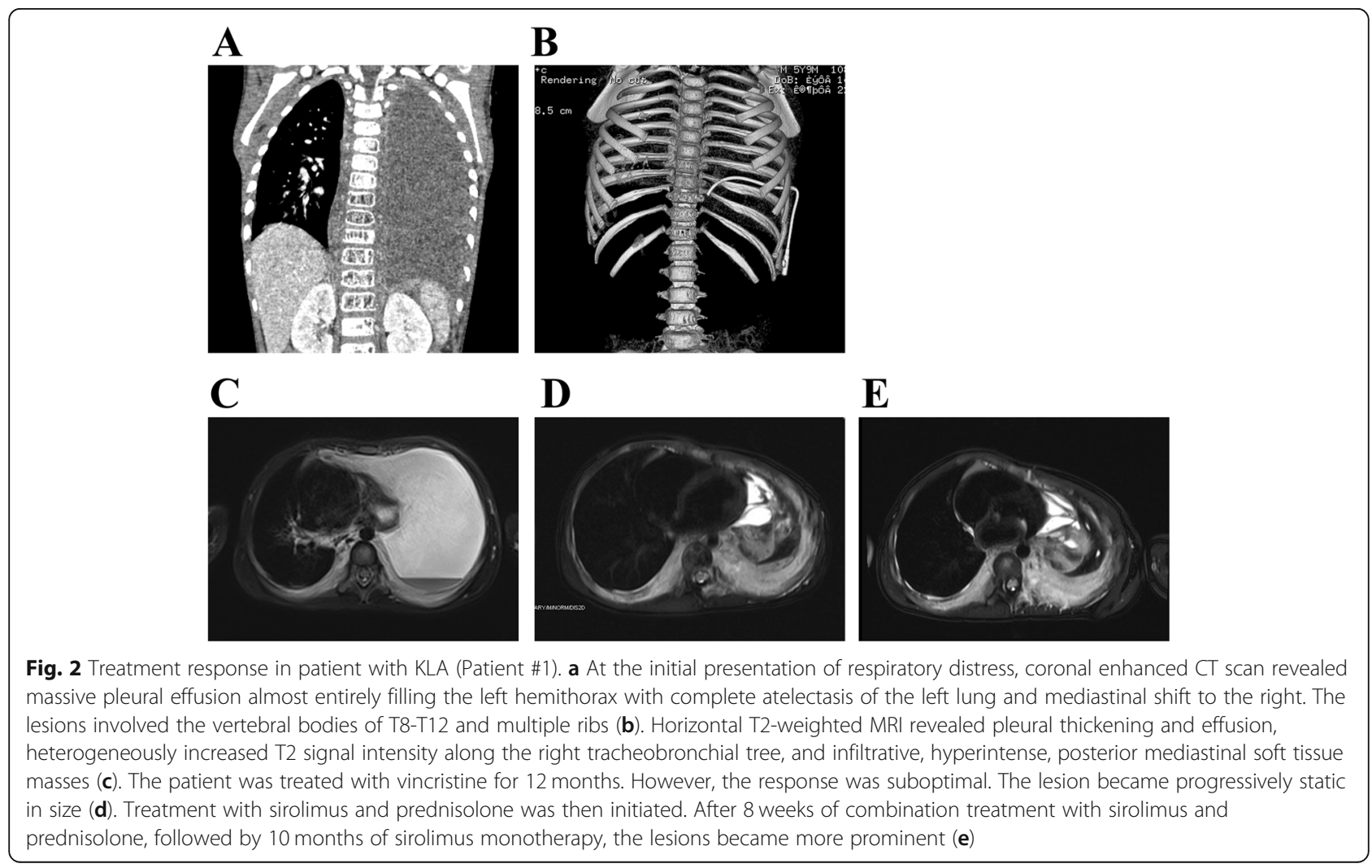




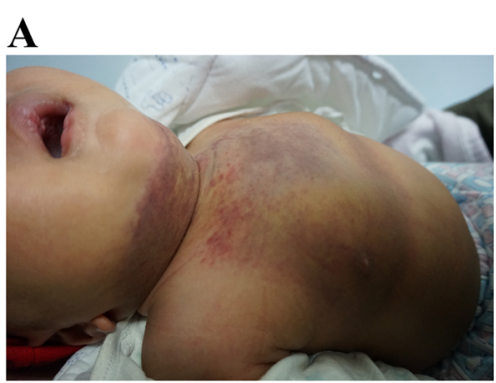

\section{B}

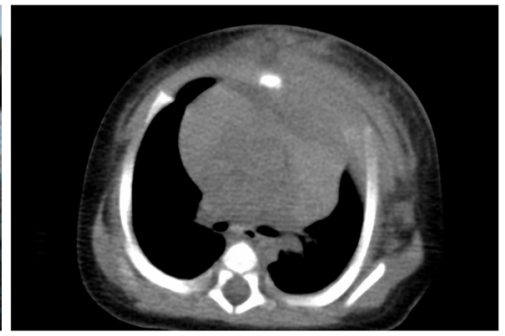

Fig. 3 KHE with cutaneous involvement. a The photograph shows an indurated and purpuric mass in the anterior neck, chest and abdominal wall (Patient \#13). Ecchymosis was evident with telangiectasia. b An unenhanced CT scan revealed an extensive soft-tissue mass with ill-defined margins throughout the anterior thoracic musculature

common. Other common imaging findings were emphysema, pneumonia and mild to severe pleural effusion. All but one patient presented with a solitary lesion. In patient \#8, an enhanced $\mathrm{CT}$ scan revealed multiple mixed sclerotic lesions in the left root of the neck, left posterior chest wall and superior mediastinum, compressing the left primary bronchus. The lesions diffusely infiltrated the vertebral bodies of $\mathrm{T} 1$ and $\mathrm{T} 6$ and the parallel ribs (Fig. 4a).

\section{Pathological findings}

All patients with KLA underwent incisional biopsy during the diagnostic workup (Fig. 1d). The histologic characteristics of KLA were dispersed and poorly marginated clusters or sheets of spindled lymphatic endothelial cells, which accompanied malformed lymphatic channels (Fig. 1e). The lymphatic origin of the lesions was confirmed by immunostaining of the lymphatic endothelial cells for CD31 (Fig. 1f) and D2-40 (Fig. 1g). The histologic findings were consistent with the diagnosis of KLA.

Specimens were taken during the active phase of KMP in five patients with KHE. The histologic hallmark of KHE was infiltrating, defined, rounded and confluent nodules, which were composed of spindle endothelial cells (Fig. 4b). These spindle endothelial cells aligned to form lymphatic channels and slit-like vascular lumina containing extravasation of erythrocyte with hemosiderin deposits. Immunohistochemical studies showed that the tumor cells were positive for CD31 (Fig. 4c), CD34 (Fig. 4d) and D2-40 (Fig. 4e).

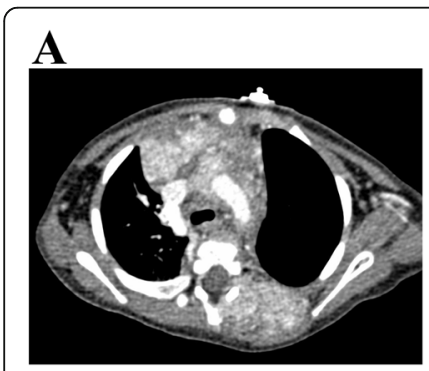

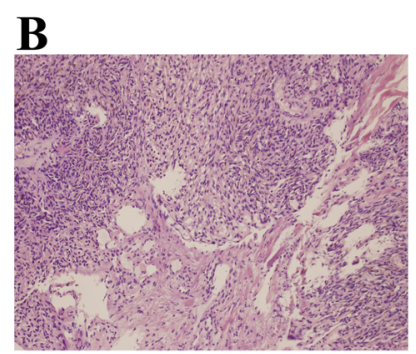

C

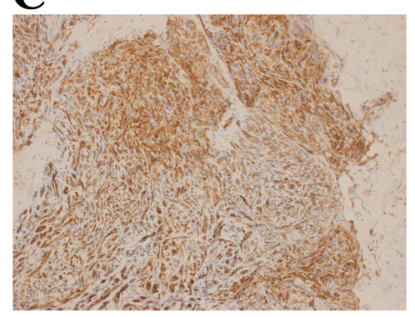

G

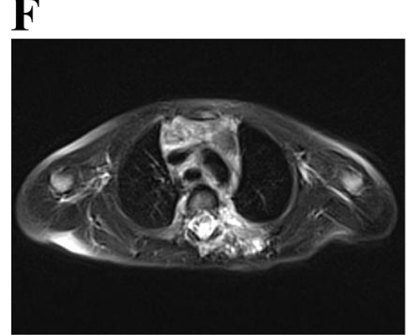

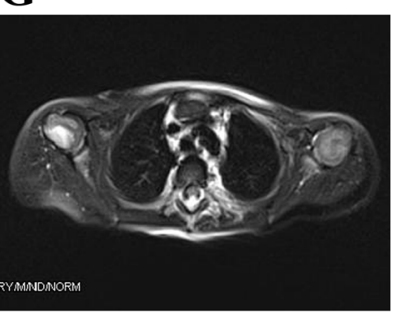

D

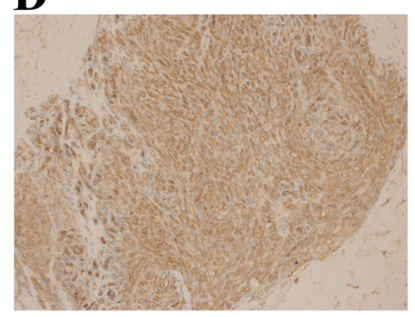

$\mathbf{H}$

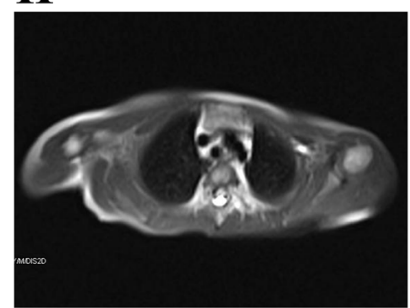

Fig. 4 Radiologic findings, pathological features and treatment response in a patient with KHE (Patient \#8). a An enhanced CT scan shows an enhanced soft-tissue mass extending from the posterior thoracic musculature to the vertebrae. Hematoxylin-eosin staining shows an abnormal proliferation of spindle cells and well-formed capillary-like vessels. Occasional slit-like or round lumens, which were comprised of closely packed spindle cells, could be seen (b). The spindle cells were positive for CD31 (c), CD34 (d), and D2-40 (e). The patient received sirolimus in combination with a short-term administration of prednisolone, followed by 22.0 months of sirolimus monotherapy. Prednisolone was successfully tapered and discontinued at 4 and 8 weeks, respectively. MRI showed obvious tumor shrinkage at $6(\mathbf{f}), 12(\mathbf{g})$, and 24 (h) months after the start of sirolimus treatment 


\section{Management}

Treatment was multimodal in patients with KLA; all patients received at least one therapeutic modality, including corticosteroids, vincristine, sildenafil, and sirolimus. No single or combination medical treatment produced consistently reproducible responses, defined as the improvement of the symptoms, shrinkage of the lesion size and/or restoration of the hematologic parameters. All patients received additional procedural therapies, including thoracotomy, thoracoscopy, chest tubes, pericardiocentesis and/or splenectomy. In three patients, there was no improvement in symptoms and/or resolution of the thrombocytopenia. Two patients required frequent platelet infusion and fresh frozen plasma to manage their thrombocytopenia and coagulopathy. Patient \#3 has been treated with combination therapy of prednisolone $(2 \mathrm{mg} / \mathrm{kg} / \mathrm{d})$ and sirolimus $\left(0.8 \mathrm{mg} / \mathrm{m}^{2}\right.$ administered twice daily). However, his response was suboptimal. $\mathrm{He}$ was advised to undergo splenectomy after a multidisciplinary discussion of his disease and treatment plan.

All but one patient with $\mathrm{KHE}$ required multimodal therapy; monotherapy was usually not sufficient to treat KMP. In 3 patients, multiple agents were given in sequence. Since 2011, the treatment most commonly administered was sirolimus plus prednisolone. This treatment regimen was effective in providing a rapid improvement of the hematopoietic parameters. After 3-4 weeks of combination treatment, the prednisolone was tapered and discontinued within the following 3-4 weeks, while sirolimus was continued.

\section{Follow-up}

The mean length of follow-up for the entire cohort was 4.5 years (range, 1.2 to 9.0 years). Liver function, blood parameters, coagulation function and imaging examinations (CT and/or MRI) were the modalities used to monitor patients. Two patients with KLA (patients \#4 and 5) suffered severe respiratory distress and repeated hemothorax. They died from acute heart failure and/or disseminated intravascular coagulopathy. Significant symptom relief was recorded in one patient with KLA who underwent splenectomy (patient \#3). There was evidence of significant improvements in the pulmonary interstitial opacities, interlobular septal thickening and pleural effusion (Fig. 1h). In one patient (patient \#1), although vincristine and sirolimus improved the associated respiratory symptoms, the patient experienced enlargement of his tumor mass and persistent mild thrombocytopenia despite prolonged sirolimus treatment (Fig. 2c-e). One patient had more additional small lesions in the liver and spleen, although he had been free of the recurrence of thrombocytopenia.

One patient with $\mathrm{KHE}$ died as a result of severe thrombocytopenia and coagulopathy despite aggressive treatments, including high doses of corticosteroids. The remaining six patients showed improvement. The KHE lesions continued to regress after the initial response, with an associated concurrent relief of symptoms (Fig. 4f-h). Five patients had been successfully tapered off treatment. Neither regrowth of the KHE nor hematologic abnormalities was observed at the last follow-up.

\section{Discussion}

The natural histories of KLA and KHE and the treatment regimens of these lesions remain unclear. This is a large number of single institutional KLA and thoracic KHE review study. Our review demonstrated that KLA shares overlapping patterns of clinical symptoms, anatomical location, imaging features and complications with KHE. The accurate diagnosis of KLA and intrathoracic KHE can be hampered by this nonspecific presentation, including indolent respiratory symptoms, thrombocytopenia, and coagulopathy.

KHEs are found in varied locations, and approximately $88 \%$ of the lesions have cutaneous manifestations. The extremities are the most common anatomic locations. Intrathoracic KHEs and multifocal lesions are extremely unusual [11]. Intrathoracic lesions have been identified in 3 and $10 \%$ of patients with KHE by two of the largest retrospective studies, both of which collecting data from more than 100 patients with KHE $[1,4]$. However, multifocal or diffuse KHE, which simultaneously involves the thorax and abdomen, has not been reported. In contrast, all patients with KLA had intrathoracic disease, and cutaneous involvement was rare. Microcystic lymphatic anomalies involving the lung parenchyma and spleen were noted in KLA [2]. Retroperitoneal lesions and noncontiguous bone destruction were also common in patients with KLA. In the present study, four patients with KLA had initially been diagnosed with pulmonary infections but failed to improve after treatment with antibiotics, prompting further diagnostic imaging.

Approximately $70 \%$ of patients with $\mathrm{KHE}$ develop KMP $[1,4]$. Consistent with previous studies, we found that all intrathoracic lesions were associated with KMP. Clinically, intrathoracic lesions tended to be more expansive and infiltrative, and were more likely to develop KMP [5-7]. KMP in KHE is a profound thrombocytopenia with coagulopathy resulting from intralesional platelet trapping, followed by the activation and consumption of platelets. It is conceivable that the abnormal lymphatic endothelial cells in KHE lesions can directly trigger platelet activation via the CLEC2/podoplanin pathway [12]. In patients with $\mathrm{KHE}$, the platelet counts are often less than $30 \times 10^{9} / \mathrm{L}$. It is now clear that KMP occurs with KHE and tufted angioma and not with infantile hemangiomas and congenital hemangiomas. 
However, thrombocytopenia and coagulopathy in KLA may overlap with KMP in KHE. Interestingly, we found that the thrombocytopenia in some patients with KLA was extremely severe, similar to that observed in patients with KHE [13]. Nonetheless, our findings suggest that the presentation of diffuse, infiltrating, intrathoracic vascular lesions (with or without extrathoracic lesions) with refractory thrombocytopenia and coagulopathy can make the diagnosis of KLA relatively straightforward.

Pathologically, KHE lesions are clearly vascular tumors. In contrast, KLAs are complex vascular anomalies and are considered to share the characteristics of both tumors and malformations [14]. In patient \#2, despite aggressive treatment, the splenic lesion progressed from a focal growth pattern to a multifocal growth pattern. This phenomenon further supports the concept that KLAs exhibit neoplasm features. As malformations, KLAs are presumed to have been present since birth [2]. A recent study revealed that KLA endothelial cells appeared inactive in supporting the formation of the vascular network, whereas KHE cells had this capacity [15]. Histologically, these lesions have similar histological characteristics. Both KLA and KHE are positive for the lymphatic marker D2-40, although the presence of nodules of spindle endothelial cells forming slit-like vascular channels is unique to KHE. In addition, the spindle endothelial cell component in KHE is primarily solid, with more defined, confluent vascularized nodules with microthrombi, glomeruloid foci and fibrin, whereas in KLA, the growth is usually sparse with poorly marginated clusters [16]. A somatic activating NRAS variant (c.182 A > G, p.Q61R) has been identified in lesional tissues from 10/11 patients with KLA. The study also indicated that the NRAS variant (c.182 A > G, p.Q61R) was absent from KHE samples, thus providing a molecular mean to further differentiate the two entities [17].

Although patients with KHE showed a wide variation in severity, recent studies have demonstrated that sirolimus monotherapy produced the best response in patients with KHE without KMP [18]. In addition, sirolimus in combination with short-term prednisolone has been proven to be effective in the treatment of refractory or severe KHE with KMP [10]. In the present report, the patients with KHE demonstrated dramatic improvement after treatment with a combination of sirolimus and prednisolone. Similar to KHEs, KLAs are uncommon, and therefore, there is a lack of controlled trials. Clinically, the majority of patients with KLA needed a combination of procedural and medical treatments. Medical therapies, including vincristine, corticosteroids, interferon and sirolimus, have been recommended for the management of KLA. However, the standard protocols remain unclear because the responses to therapy are variegated and unpredictable $[2,9,13,19$,
20]. Compared with KHE, KLA appears to be more refractory to medical therapies. Despite aggressive multimodal treatment, the mortality rate of KLA is notably high [2].

Splenectomy was performed in one of our patients with KLA due to his poor response to a combination treatment of sirolimus and prednisolone. Interestingly, this patient experienced notable improvement in his symptoms and complications after splenectomy. Most importantly, the amelioration of the interlobular septal thickening was maintained. In the report by Croteau et al. [2], splenectomy was performed in 3 patients with KLA, with two responding with the normalization of platelet levels. These phenomena raise the question of whether splenic lesions could have a stronger preactivating effect on platelets and therefore on KLA aggravation. It is conceivable that rapid advances in medical science and any information or advice on diagnoses, treatment durations, or surveillance guidelines will facilitate the development of important new approaches for the management of patients with KLA and KHE.

\section{Conclusions}

There are some clinical and histological similarities between KLA and KHE. However, KLA seems to be a more complex, multifocal lymphatic anomaly, which is different from KHE with respect to behavior, radiologic imaging, histopathologic features and response to therapy. Information is sparse regarding the pathogenesis of these aggressive vascular anomalies and the mechanism or mechanisms underlying the associated thrombocytopenia and coagulopathy. Our study highlights the importance of multidisciplinary efforts in diagnosing and managing KLA and KHE. Given the rarity of KLA and KHE, large collaborative studies are essential to further identify effective treatment regimens for these life-threatening vascular anomalies.

\section{Additional file}

Additional file 1 Table S1. Clinical Characteristics of patients with KLA or KHE. (DOCX $25 \mathrm{~kb}$ )

\section{Abbreviations \\ CT: Computed tomography; FlB: Fibrinogen; KHE: Kaposiform hemangioendothelioma; KLA: Kaposiform lymphangiomatosis; KMP: Kasabach-Merritt phenomenon; MRI: Magnetic resonance imaging}

\section{Acknowledgements}

We thank the patients and their parents for their co-operation and support, and for providing consent for publication. We also thank the study and hospital nurses for their assistance with the management of the patients.

\section{Authors' contributions}

YJ, SC, SP, CX and LL were involved in the clinical management of these patients and collected clinical details of this study. YJ reviewed the literature, 
and drafted the manuscript. YJ and SYC reviewed the manuscript. All authors read and approved the final manuscript.

\section{Funding}

This work was supported by grants from the National Natural Science Foundation of China (Grant No: 81401606 and 81400862), the Key Project in the Science \& Technology Program of Sichuan Province (Grant No: 19ZDYF1454), and the Science Foundation for Excellent Youth Scholars of Sichuan University (Grant No: 2015SU04A15).

\section{Availability of data and materials}

The datasets used and/or analyzed during the current study available from the corresponding author on reasonable request.

\section{Ethics approval and consent to participate}

The study was approved by the Ethics Committee of the West China Hospital of Sichuan University. Written informed consent was obtained from the patients' parents, according to the provisions of the Declaration of Helsinki.

\section{Consent for publication}

Written informed consent for publication this study was obtained from the patients' parents. Copies of the signed informed consent forms are available for review by the Series Editor of BMC Pediatrics.

\section{Competing interests}

The authors declare that they have no competing interests, either financial or non-financial, that could be perceived as prejudicing the impartiality of the research reported.

\section{Author details}

'Division of Oncology, Department of Pediatric Surgery, West China Hospital of Sichuan University, Chengdu 610041, China. ${ }^{2}$ Pediatric Intensive Care Unit, Department of Critical Care Medicine, West China Hospital of Sichuan University, \#37\# Guo-Xue-Xiang, Chengdu 610041, China. ${ }^{3}$ Department of Radiology, West China Hospital of Sichuan University, Chengdu 610041, China. ${ }^{4}$ Laboratory of Pathology, West China Hospital of Sichuan University, Chengdu 610041, China.

Received: 17 December 2018 Accepted: 26 June 2019

Published online: 05 July 2019

\section{References}

1. Croteau SE, Liang MG, Kozakewich HP, Alomari Al, Fishman SJ, Mulliken JB, Trenor CR. Kaposiform hemangioendothelioma: atypical features and risks of Kasabach-Merritt phenomenon in 107 referrals. J Pediatr. 2013;162(1):142-7.

2. Croteau SE, Kozakewich HP, Perez-Atayde AR, Fishman SJ, Alomari Al, Chaudry G, Mulliken JB, Trenor CR. Kaposiform lymphangiomatosis: a distinct aggressive lymphatic anomaly. J Pediatr. 2014;164(2):383-8.

3. Safi F, Gupta A, Adams D, Anandan V, McCormack FX, Assaly R. Kaposiform lymphangiomatosis, a newly characterized vascular anomaly presenting with hemoptysis in an adult woman. Ann Am Thorac Soc. 2014;11(1):92-5.

4. Ji Y, Yang K, Peng S, Chen S, Xiang B, Xu Z, Li Y, Wang Q, Wang C, Xia C, et al Kaposiform haemangioendothelioma: clinical features, complications and risk factors for Kasabach-Merritt phenomenon. Brit J Dermatol. 2018;179(2):457-63.

5. Iwami D, Shimaoka S, Mochizuki I, Sakuma T. Kaposiform hemangioendothelioma of the mediastinum in a 7-month-old boy: a case report. J Pediatr Surg. 2006;41(8):1486-8.

6. San MF, Spurbeck W, Budding C, Horton J. Kaposiform hemangioendothelioma: a rare cause of spontaneous hemothorax in infancy. Review of the literature. J Pediatr Surg. 2008;43(1):e37-41.

7. Duan L, Renzi S, Weidman D, Waespe N, Chami R, Manson D, Cada M, Carcao M. Sirolimus treatment of an infant with intrathoracic Kaposiform Hemangioendothelioma complicated by life-threatening pleural and pericardial effusions. J Pediatr Hematol Oncol. 2018. https://doi.org/10.1097/ MPH.0000000000001268. [Epub ahead of print].

8. Enjolras O, Wassef M, Mazoyer E, Frieden IJ, Rieu PN, Drouet L, Taieb A, Stalder JF, Escande JP. Infants with Kasabach-Merritt syndrome do not have "true" hemangiomas. J Pediatr. 1997;130(4):631-40.

9. Ozeki M, Fujino A, Matsuoka K, Nosaka S, Kuroda T, Fukao T. Clinical features and prognosis of generalized lymphatic anomaly, Kaposiform
Lymphangiomatosis, and Gorham-stout disease. Pediatr Blood Cancer. 2016; 63(5):832-8.

10. Ji Y, Chen S, Xiang B, Li K, Xu Z, Yao W, Lu G, Liu X, Xia C, Wang Q, et al. Sirolimus for the treatment of progressive kaposiform

hemangioendothelioma: a multicenter retrospective study. Int J Cancer. 2017;141(4):848-55.

11. Ji Y, Chen S, Li L, Yang K, Xia C, Li L, Yang G, Kong F, Lu G, Liu X. Kaposiform hemangioendothelioma without cutaneous involvement. J Cancer Res Clin. 2018;144(12):2475-84.

12. O'Rafferty C, O'Regan GM, Irvine AD, Smith OP. Recent advances in the pathobiology and management of Kasabach-Merritt phenomenon. $\mathrm{Br}$ J Haematol. 2015;171(1):38-51.

13. Fernandes VM, Fargo JH, Saini $S$, Guerrera MF, Marcus L, Luchtman-Jones L, Adams D, Meier ER. Kaposiform lymphangiomatosis: unifying features of a heterogeneous disorder. Pediatr Blood Cancer. 2015;62(5):901-4.

14. Boland JM, Tazelaar HD, Colby TV, Leslie KO, Hartman TE, Yi ES. Diffuse pulmonary lymphatic disease presenting as interstitial lung disease in adulthood: report of 3 cases. Am J Surg Pathol. 2012;36(10):1548-54.

15. Glaser K, Dickie P, Dickie BH. Proliferative cells from Kaposiform Lymphangiomatosis lesions resemble mesenchyme stem cell-like Pericytes defective in vessel formation. J Pediatr Hematol Oncol. 2018;40(8):e495-504.

16. Goyal P, Alomari Al, Kozakewich HP, Trenor CR, Perez-Atayde AR, Fishman SJ, Greene AK, Shaikh R, Chaudry G. Imaging features of kaposiform lymphangiomatosis. Pediatr Radiol. 2016;46(9):1282-90.

17. Barclay SF, Inman KW, Luks VL, Mclntyre JB, Al-Ibraheemi A, Church AJ, Perez-Atayde AR, Mangray S, Jeng M, Kreimer SR, et al. A somatic activating NRAS variant associated with kaposiform lymphangiomatosis. Genet Med. 2018. https://doi.org/10.1038/s41436-018-0390-0 Epub ahead of print.

18. Ji Y, Yang K, Chen S, Peng S, Lu G, Liu X. Musculoskeletal complication in kaposiform hemangioendothelioma without Kasabach-Merritt phenomenon: clinical characteristics and management. Cancer Manag Res. 2018;10:3325-31.

19. Triana P, Dore M, Cerezo VN, Cervantes M, Sanchez AV, Ferrero MM, Gonzalez MD, Lopez-Gutierrez JC. Sirolimus in the treatment of vascular anomalies. Eur J Pediatr Surg. 2017;27(1):86-90.

20. Wang Z, Li K, Yao W, Dong K, Xiao X, Zheng S. Successful treatment of kaposiform lymphangiomatosis with sirolimus. Pediatr Blood Cancer. 2015; 62(7):1291-3.

\section{Publisher's Note}

Springer Nature remains neutral with regard to jurisdictional claims in published maps and institutional affiliations.

Ready to submit your research? Choose BMC and benefit from:

- fast, convenient online submission

- thorough peer review by experienced researchers in your field

- rapid publication on acceptance

- support for research data, including large and complex data types

- gold Open Access which fosters wider collaboration and increased citations

- maximum visibility for your research: over $100 \mathrm{M}$ website views per year

At $\mathrm{BMC}$, research is always in progress.

Learn more biomedcentral.com/submissions 